\title{
POWER CUSTOMER SATISFACTION ANALYSIS USING ANALYTIC HIERARCHY PROCESS
}

\author{
Rabah Medjoudj* \\ Lamos Laboratory, Electrical engineering department \\ University of Bejaia, Algeria \\ Email:medjoudj@yahoo.fr, Fax:+21334218716 \\ Aicha Laifa \\ Soperie, Electrical engineering society \\ Bejaia, Algeria \\ Email: a.laifa06@gmail.com \\ Djamil Aissani \\ Lamos Laboratory, Operational research department \\ University of Bejaia, Algeria \\ Emai:lamos_bejaia@hotmail.com
}

\begin{abstract}
In the context of global financial crisis, electricity distribution companies show some concern and reluctance towards investments under the pretext of inertia and backwardness of depreciation. In this paper, it is shown that it is possible to safeguard the interests of consumers and business by investing in a rational manner. This issue has been taken over by introducing two different methods, namely: Cost Benefit Analysis and Analytic Hierarchy Process. The obtained results using both methods converge to strategies more or less similar highlighting the relevance of investments. The application developed in this paper confirms that reliability criteria are significant stake in the performance of a business and are an important asset for new projects justification.
\end{abstract}

\section{Key Words:}

Electrical distribution system, decision-making criteria, reliability indices, customer satisfaction.

\section{INTRODUCTION:}

In this paper, power customer expectation and enterprise financial success are involved by reliability criteria. For reliability and its cost evaluation, a variety of indices have been developed in power systems area (Billinton and Wangdee 2007) (Medjoudj et al 2009) such as: Expected Frequency of Load Curtailment (EFLC), Expected Duration of Load Curtailment (EDLC), Expected Duration of a Curtailment (EDC) and Expected Energy Not Supplied (EENS). Mathematically, customer satisfaction can be developed as follows: $n$ important customer wants (power availability, power quality, proper and aesthetic environment, safety supply, and etc) denoted $E_{1}, E_{2}, \ldots, E_{n}$ are linked to $m$ critical performance characteristics (EFLC, EDLC, EDC, EENS, and etc) denoted $Y_{1}, Y_{2}, \ldots, Y_{m}$. The thresholds of $Y_{1}, Y_{2}, \ldots, Y_{m}$ are $D_{1}, D_{2}, \ldots, D_{m}$ respectively. The degree of customer satisfaction on $E_{i}$ can be expressed as the probability that the critical performance characteristics values don't exceed the threshold values and can be written as: $S_{i}=\operatorname{Pr}\left(Y_{j} \leq D_{j}\right), i=1,2, \ldots, m$ (Yang G. 2007). The aim of this paper is to develop applications of multi-criteria methods for decision making in electrical distribution system for customer satisfaction and financial success of the company.

\footnotetext{
${ }^{*}$ Corresponding author
} 
A particular attention is made to the Analytic Hierarchy Process (AHP) because this method makes the selection process very transparent with a great benefit for a company assuring public services.

Omkarprasad et al (2006) have reviewed a total of 150 AHP application papers (1980-2003) providing an informative summary kit for researchers and practitioners for their future works. However, AHP process has been applied lately to solve the problems of electric power system. It is used by Negim et al (2003) as an expert system to identify the vulnerability of special protection schemes (SPS) and by Malik et al (2003) for the impact evaluation and logical prioritization of demand side resources to planning criteria. In reference (Chen H.H et al 2009), the authors have jointly used ANP and AHP processes for a strategic selection of a feeder management system, applied to the power industry in china. In the present paper, the proposed alternatives constituting decision-maker strategies are particularly governed by reliability criteria. From a practical standpoint, the obtained results provide decision-makers with a range of choices enabling them to target a well-defined goal and take appropriate action according to the company means.

\section{RELIABILITY IMPROVMENTS}

Nearly every electricity utility computes reliability indices on an annual basis. The most important reliability indices involving decision-making criteria are given as follows:

$$
\begin{aligned}
& E F L C=\sum_{k=1}^{n} \lambda_{k} \quad(\text { fault } / \mathrm{yr}) \\
& E D L C=\sum_{k=1}^{n} \lambda_{k} T_{k} \quad(\mathrm{hrs} / \mathrm{yr}) \\
& E E N S=L .(E D L C)(\mathrm{kWh} / \mathrm{yr})
\end{aligned}
$$

Where: $\lambda_{k}, T_{k}$ are respectively, failure rate and failure duration of an item $k$ and $L$ is the load curtailed at a considered load point. To improve the reliability level, technical and organizational measures are considered during system planning and operation. These actions are listed regrouping three principal alternatives $\mathrm{A}_{\mathrm{i}},(\mathrm{i}=2,3$ and 4$)$ for which is added the actual state of the system as the fourth one and denoted $\mathrm{A}_{1}$.

- Alternative 1, $\left(\mathrm{A}_{1}\right)$ : Do nothing new and keeps the system functioning routinely,

- Alternative 2, $\left(\mathrm{A}_{2}\right)$ : Install faults detectors at each sub-station, consequently the time $t_{g s}$ in the fault research fails from $15.0 \mathrm{~min}$ to $05.0 \mathrm{~min}$.

- Alternative 3, $\left(\mathrm{A}_{3}\right)$ : Add to alternative $\left(\mathrm{A}_{2}\right)$, remote control switches on outgoing MV lines to reduce the number of customers concerned by a failure.

- Alternative 4, $\left(\mathrm{A}_{4}\right)$ : Undergrounding overhead circuits and changing the aging cables (sections exceeding the threshold number of joints).

From practical standpoint, this application allows to highlight the goodness of each measure to the system performances by simple comparison of reliability indices. The obtained results at this stage of the investigation constitute a prerequisite knowledge aiding to comfort expert judgment for weights association to criteria in the following sections.

\section{COST-BENEFIT ANALYSIS}

Cost -benefit analysis (CBA) is a worldwide used technique in decision-making. CBA evaluates the costs and benefits of the alternatives on monetary basis. The actual formulas of cost factors vary with the applications. The balance is achieved by minimizing the total cost (TOC) gathering all costs in three terms shown in the following:

Total cost $(\mathrm{TOC})=$ Utility Cost $(\mathrm{UC})+$ Customer Interruption Cost (CIC) + Losses Cost (LC)

The application is carried out for the whole alternatives described above and results are obtained. 
The cost-benefit analysis aids to evaluate the importances of sub-criteria relative to costs. For example, the CIC is more important than the LC. These results can be compared to those obtained using the following method "AHP" which considers multiple criteria than the costs.

The formula currently used for the cost function is given by the following equation.

$$
\operatorname{Min} . . . \mathrm{E}\left[\sum_{t=1}^{T} \frac{U C_{t}+C I C_{t}+L C_{t}}{(1+i)^{t}}-\frac{V_{T+1}}{(1+i)^{T+1}}\right]
$$

Where:

$E$ : the operator of expectation, taking in account the random variables which affect the system; $T$ : the horizon of planning; $t$ : the index of time step; $V_{T+1}$ : the practical value of the system at the end period of planning; $i$ : the present worth rate characterizing the financial policy of the company.

Let, $I_{k}$, the unit capital cost of an item $k$. The annual capital cost updated of an item $k$ is given by $I_{a k}=I_{k} \frac{\gamma^{n}(\gamma-1)}{\left(\gamma^{n}-1\right)}$; with $\gamma=i+1$ and $n$, the year of use. The total cost of $k^{\prime}$ items over the period $T=\left[t_{1}, t_{2}\right]$ of planning updated constitutes the utility cost (UC) and given as:

$$
U C_{t}=\sum_{t=t_{1}}^{t_{2}} \sum_{k=1}^{k^{\prime}} I_{a k}(t) \gamma^{-t}
$$

The maximum losses correspond to the value of active power $P_{\max }$. in the overhead transmission lines, underground cables and sub-stations. The annual cost of losses in a section $k$ is $R_{k}=\left(K_{p}+K_{w} \cdot \theta \cdot T_{a}\right) P_{\max } \cdot v$, with, $K w$ : the tariff of kilowatt-hour $(\mathrm{kWh}) ; K p$ : the tariff of kilowatt $(\mathrm{kW}) ; \theta$ : the ratio defining the use of the network; $v:$ The demand variation factor and $T a=8760 \mathrm{~h}$. If the network contains $k^{\prime}$ sections, the total updated losses cost (LC) is:

$$
L C_{t}=\sum_{t=t_{1}}^{t_{2}} \sum_{k=1}^{k^{\prime}} R_{k} \cdot \gamma^{-t}
$$

The customer interruption is felt mainly by the user of the network. This customer interruption cost (CIC) is a function of reliability indices, and given by: $C I C=L\left(K_{p} \cdot E F L C^{2}+K_{w} \cdot E D L C\right) \quad$ or $\left.C I C=L \cdot K_{p} \cdot E F L C^{2}+K_{w} \cdot E N N S\right)$. The CIC is a quadratic function of the number of failures. This valorization directs the investments in priority on the most disturbed zones. The updated customer interruption cost is then:

$$
C I C_{t}=K_{W} \sum_{t=t_{1}}^{t_{2}} E E N S \cdot \gamma^{-t}+K_{\rho} \sum_{t=t_{1}}^{t_{2}} L \cdot E F L C^{2} \cdot \gamma^{-t}
$$

Finally, the optimum reliability level is determined by minimizing the Expected Cost

$$
E C O S T_{t}=U C_{t}+L C_{t}+C I C_{t}
$$

The application is carried out for the whole alternatives where the common parameters for computation are as follows: $v=1.07, T=5$ years; $K_{w}=0.6 U S \$ ; K_{p}=0.23 U S \$ ; \theta=30 \%$ and $T_{a}=8760 \mathrm{~h}$. From practical point of view, the alternatives are described with the enumeration of items costs. It will be noted that for each alternative, the electric power losses are processed using load flow techniques.

- Alternative $A_{1}$ is carried without investments; 
- Alternative $\mathrm{A}_{2}$ corresponds to the installation of 205 fault indicators on the system, where the unit cost is $I_{f}=600 U S \$$.

- Alternative $\mathrm{A}_{3}$ corresponds to $\mathrm{A}_{2}$ with the addition of 5 reclosers in line. The unit cost of a recloser in line is $I_{r}=3500 U S \$$.

- Alternative $\mathrm{A}_{4}$, as described above, corresponds to undergrounding $2.75 \mathrm{~km}$ of cable $\left(70 \mathrm{~mm}^{2}\right)$ and replacing $7.25 \mathrm{~km}$ of oldest sections. The cost of the cable is $18000 \mathrm{US} \$$ per $\mathrm{km}$.

The obtained results for costs assessment using Matlab 6.5 software package are dressed in table 1.

Table 1 The matrix of costs versus alternatives

\begin{tabular}{lccl}
\hline & & & \\
Worth rate values & $i=0.02$ & $i=0.03$ & $i=0.04$ \\
\cline { 2 - 4 } A1ternatives & & & \\
$n_{1}$ & 52108 & 50629 & 49215 \\
$\mathrm{~A}_{2}$ & 49671 & 53683 & 57655 \\
$\mathrm{~A}_{3}$ & 33923 & 38863 & 43625 \\
$\mathrm{~A}_{4}$ & 858320 & 833970 & 810680 \\
\hline
\end{tabular}

\section{ANALYTIC HIERARCHY PROCESS}

The AHP method can be summarized as follows (Triantaphillou et al 1997):

1) Model the problem as a hierarchy containing the decision goal, the alternatives for reaching it, and the criteria for evaluating the alternatives.

2) Establish priorities among the elements of the hierarchy by making a series of judgments based on pair-wise comparisons of the elements.

3) Synthesize these judgments to yield a set of overall priorities for the hierarchy.

4) Check the consistency of the judgments.

5) Come to a final decision based on the results of this process.

6) Analyze the sensitivity to changes in judgment to study the margin of stability and the decision.

In this part of the paper, AHP is applied to select the best alternative to provide customer satisfaction and financial success. As for a first step, five selection criteria $C_{j}$ (for $j=1,2,3,4,5$ ) were considered to be relevant to this case study and were respectively: cost, reliability, availability, maintainability and power quality. For the cost criterion $C_{1}$, are associated three sub-criteria such as: UC, LC and CIC. For the reliability criterion $C_{2}$, are associated three sub-criteria respectively as: Aging or degradation increasing ( $\mathrm{Ag}$ ) highlighted by the behavior of forecasts, EFLC and EDLC. Four alternatives were selected denoted by $\mathrm{A}_{\mathrm{i}}$ (for $\left.i=1,2,3,4\right)$ already developed in section 3 .

The second step is the pair-wise comparison of the importance of criteria, this is done by assigning a weight between 1 and 9, following Saaty (1990), and the reciprocal of this value is then assigned to the other criterion in the pair. The third step is to extract the relative importance implied by the previous comparisons. In the fourth step, is cheeked the consistency of judgments. The results of the operations conducted in the previous steps are gathered in table 2.

We note that the priority vector $P_{j}$ (eigenvector), the maximum eigenvalue $\lambda_{\max }$, the consistency index $C I$ and the consistency ratio CR (Saaty 2008) were processed using a program under Matlab 6.5 software package, where the algorithm is given as follows:

Step0: Read the inputs such as, the judgment matrix $\operatorname{order} N$, the elements of the judgment matrix $a_{i j}, i=1: N, j=1: N$ and the relative consistency index $R C I$ value corresponding to $N$ value. 
Step1: Compute the geometric means, $m(i) \longleftarrow\left(\prod_{j=1}^{N} A(i, j)\right)^{\frac{1}{N}}$ for $i=1: N$;

Step2: Compute the priorities, $P(i) \longleftarrow \frac{m(i)}{\sum_{l=1}^{N} m(l)}$ for $i=1: N$;

Step3: Compute the spectra of the matrix $A A, S P A \longleftarrow \operatorname{eig}(A A)$;

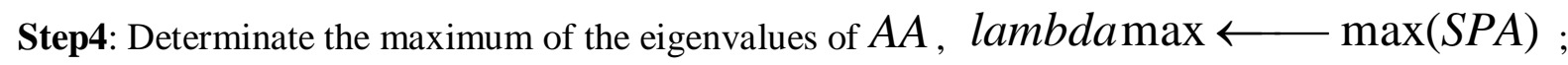

Step5: Compute the consistency index $C I, C I \longleftarrow \frac{(\text { lambdamax }-N)}{(N-1)}$;

Step6: Compute the consistency rate $C R, C R \longleftarrow \frac{C I}{R C I}$;

Step7: End.

Table 2 Comparison matrices and local priorities

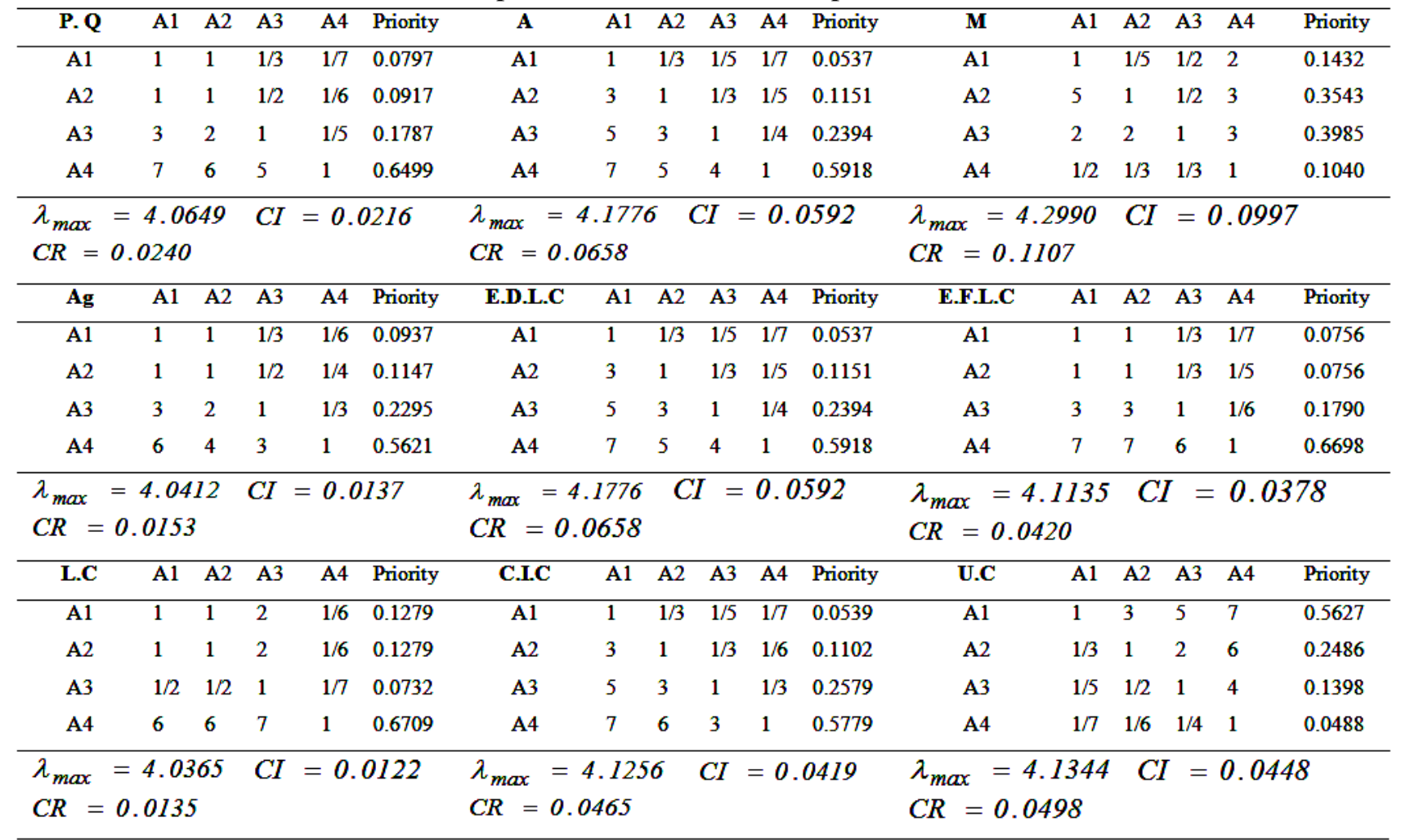

In table 3, is given a synthesis corresponding to the rankings of the four alternatives against the nine criteria and sub-criteria confounded. With this synthesis, we come to the final step involving the final decision of this process. It will be noted that this work constitutes an application to a real case study and concern a part of Sonelgaz system of Bejaia city, Algeria, where the electricity market is not liberal but a monopoly one. The decision maker is a multidisciplinary group composed of electric network specialist, a reliability engineer, an economist and the head of budget. 
For customer satisfaction, based on the four alternatives proposed initially, the highest priority is given to alternative $\mathrm{A}_{4}$. Consequently, the investments are oriented to the undergrounding of overhead circuits and to the replacement of aging equipment.

Table 3 Synthesizing to obtain the final results

\begin{tabular}{|c|c|c|c|c|c|c|c|c|c|c|}
\hline Criteria & & $\begin{array}{c}\mathbf{C} \\
0.5027\end{array}$ & & & $\begin{array}{c}\mathbf{R} \\
0.2715\end{array}$ & & $\begin{array}{c}\mathbf{A} \\
0.1185\end{array}$ & $\begin{array}{c}\mathbf{M} \\
0.0721\end{array}$ & $\begin{array}{c}\text { P.Q } \\
0.0351\end{array}$ & $\begin{array}{l}\text { Overall } \\
\text { priority }\end{array}$ \\
\hline Sub-criteria & U.C & C.I.C & L.C & $\mathbf{A g}$ & E.F.L.C & E.D.L.C & & & & \\
\hline $\begin{array}{l}\text { Global Weights } \\
\text { (criteria x sub- } \\
\text { criteria) }\end{array}$ & 0.6910 & 0.2176 & 0.0914 & 0.1047 & 0.6370 & 0.2583 & “ & “ & “ & \\
\hline $\mathbf{A}_{1}$ & 0.5627 & 0.0539 & 0.1279 & 0.0937 & 0.0756 & 0.0537 & 0.0537 & 0.1432 & 0.0797 & 0.2670 \\
\hline $\mathbf{A}_{2}$ & 0.2486 & 0.1102 & 0.1279 & 0.1147 & 0.0756 & 0.1151 & 0.1151 & 0.3543 & 0.0917 & 0.1710 \\
\hline $\mathbf{A}_{3}$ & 0.1398 & 0.2579 & 0.0732 & 0.2295 & 0.1790 & 0.2394 & 0.2394 & 0.3985 & 0.1787 & 0.1810 \\
\hline $\mathbf{A}_{4}$ & 0.0488 & 0.5779 & 0.6709 & 0.5621 & 0.6698 & 0.5918 & 0.5918 & 0.1040 & 0.6499 & 0.3810 \\
\hline
\end{tabular}

\section{CONCLUSION}

For the electrical distribution system, we can formulate the management as a set of decisions themselves based on various technical and organizational measures. All these measures are based on the reliability aspects which need a perfect knowledge of data, their processing and their interpretations. The trend of interruptions frequency highlighted by forecasts models has led to poor judging the quality of service offered by the current network and therefore has encouraged the managers to consider customer satisfaction and reduce the financial damage caused by the nondistributed energy. Although, the cost-benefit analysis and AHP are methods with different concepts, they converge to invest need. Based on the obtained results, the retained strategy is the one oriented on overhead circuits undergrounding and aging equipments replacement.

\section{REFERENCES}

Billinton R and Wangdee W. (2007), Reliability-based transmission reinforcement planning associated with large-scale wind farms, IEEE Transactions on power systems,(22),1,34- 41.

Medjoudj R, Aissani D , Boubakeur, A and Haim, KD. (2009), Interruption modeling in electrical distribution system using Weibull-Markov Model, IMechE Proceedings, Part O: Journal of risk and reliability, 223(2), 145-189.

Yang G. (2007), Life cycle reliability engineering, John Wiley \& Sons, New Jersy.

Omkarparsad S.V. and Sushil.K. (2006), Analytical hierarchy process: An overview of applications, E.J.O.R,169, 1-29.

Negim K.A., Suryanarayanan S., Gorur R. and Farmer R.G. (2003), The application of analytic hierarchy process to analyze the impact of hidden failures in special protection schemes, Electric power systems research, 63, 191-196.

Malik A.S. and Sumaoy C.U. (2003), Analytic hierarchy process approach in distribution utility local IRP, Electrical power and energy systems, 25, 623-631.

Chen H.H., Lee A.H.I. and Hang H-Y. (209), A model for strategic selection of feeder management systems: A case study, Electrical power and energy systems, DOI: 10.1016/j. ijepes,1-7.

Triantaphyllou, E., Kovalerchuk, B., Mann Jr, L. and Knapp, G.M. (1997), Determining the most important criteria in maintenance decision making, Journal of quality maintenance engineering,3(1), 16-28.

Saaty, T.L. (1990), How to make decision: The analytic hierarchy process, European journal of operational research, 48, 9-26. 
Saaty, T.L. (2008), Decision making with the analytic hierarchy process, Int.J. Services Sciences, 1(1), 83-97. 